\title{
ECOPHYSIOLOGY OF SELECTED CANDIDA SPECIES ISOLATED FROM DIFFERENT TYPES OF UTILITY WATER UNDER LABORATORY CONDITIONS
}

\author{
BIEDUNKIEWICZ, A. \\ Department of Mycology, Faculty of Biology and Biotechnology, \\ University of Warmia and Mazury in Olsztyn \\ 1A Oczapowskiego St. 10-917 Olsztyn, Poland \\ (phonelfax: +48-89-523-42-95) \\ *Corresponding author \\ e-mail: alibi@uwm.edu.pl \\ (Received $1^{\text {st }}$ Dec 2014; accepted $20^{\text {th }}$ Feb 2015)
}

\begin{abstract}
The ability of four microfungi species from the potential pathogens group (Candida albicans, C. guilliermondii, C. krusei and C. tropicalis) to proliferate utility water was examined under controlled laboratory conditions and the enzymatic activity of these microfungi was tested. The experiment found that all microfungi retained their capacity for growth under controlled laboratory conditions. The enzymatic activity of the investigated species was at a high level before multiplication and was reduced by approximately 5\% after controlled multiplication under laboratory conditions. All microfungi formed blastospores and pseudomycelium and their arrangement was characteristic for each species. Studies have shown that water can also be a "habitat" for microfungi as numerous fungal species may find favorable trophic and growth conditions in water, which directly affect the rate of metabolic processes.
\end{abstract}

Keywords: ecophysiology of microfungi, Candida sp., survival in the water utility

\section{Introduction}

The presence of fungi, especially yeast-like, in different types of water is welldocumented (Biedunkiewicz et al., 2007; Biedunkiewicz, 2011; Biedunkiewicz and Schulz, 2012; Biedunkiewicz et al., 2013). Many authors have evaluated diverse aspects of purity in freshwater (Wurzbacher et al., 2010), seawater (Vogel et al., 2007), surface waters (Parveen et al., 2011) and across the whole water profile (Bis et al., 2013; Shearer et al., 2007), in outdoor (Biedunkiewicz et al., 2007; Vogel et al., 2007) and indoor baths (Rasti et al., 2012), in drinking water (Biedunkiewicz and Schulz, 2012) and even in municipal fountains (Biedunkiewicz, 2009).

To date, preliminary monitoring studies on the biological and species diversity of yeast-like fungi have evaluated the mycological purity in different types of water resources in a sanitary and epidemiological context (Biedunkiewicz, 2007; Dynowska, 1995; Dynowska et al., 2001). A successive increase in the number of yeast-like fungi in water is most often associated with progressive eutrophication and accumulation of organic and inorganic contamination of a different origin (Dynowska, 1995). Fungi adapt very quickly to new and frequently changing conditions in the aquatic environment thanks to an enzymatic capacity allowing them to produce adaptation enzymes. In waters destined for recreation (for instance, in different types of baths) among allochthonous microorganisms that are important from a medical perspective, there are also fungi that present a risk to humans and animals (Dynowska et al., 2013). In many cases, they may be regarded as general indicators of water quality 
(Biedunkiewicz, 2007; Dynowska, 1995; Dynowska et al., 2001; Dynowska, 1993a; Kiziewicz, 2007).

Admittedly, there is a lack of officially-published epidemiological data on the correlation between microbial density in water and infections in humans. However, the presence of species featured on the lists of potential anthropogenic pathogens suggests such potential and water reservoirs may be a serious source of fungal infections of different etiology (Dynowska et al., 2013).

A question arises: do fungi "treat" water as a specific habitat for multiplication, growth and development or only as a site of migration between the individual parts of the biosphere (aerosphere, human onthosphere or lithosphere)?

With this in mind, it was attempted to investigate under controlled laboratory conditions the capacity for the multiplication of selected potentially-pathogenic fungi originating from lake water, an indoor swimming pool, a drinking tap and bottled water. In addition, the enzymatic activity of the tested fungi was evaluated to determine the degree of their pathogenicity. This parameter was studied both before and after culturing.

\section{Materials and methods}

\section{Biological material}

Four fungal species were analyzed from potential pathogens that are most frequently isolated from different types of water. These were: Candida albicans (Robin) Berkhout (1923) - BSL - 2, Candida tropicalis (Castellani) Berkhout (1923) - BSL 1, Candida guilliermondii (Castellani) Langeron and Guerra (1938) - BSL 1, and Candida krusei (Castellani) Berkhout (1923) - BSL 2.

\section{Diagnostic pathway on modified media}

Cultures on media with lake water, a swimming pool water and drinking water filtered through sterile membrane filter with a $0.22 \mu \mathrm{m}$ pore diameter were used to assess the multiplication capacity of the selected fungi under laboratory conditions. Based on such types of filtered water, solid Sabouraud's medium and Nickerson's medium were prepared for microcultures. Some of the filtered water was stored at $+4^{\circ} \mathrm{C}$ for $48 \mathrm{~h}$ and isolates of the tested fungi were added directly into it. All observations of cultures in filtered water were performed supravitally in a suspended drop on a slide placed in a humid incubation chamber. To verify the survivability of the investigated strains, supravital mounts with methylene blue were prepared after $48 \mathrm{~h}$ ( 2 days), $72 \mathrm{~h}$ ( 3 days), $154 \mathrm{~h}$ (7 days), $328 \mathrm{~h}$ (14 days) and $720 \mathrm{~h}$ (30 days).

For each type of water, another diagnostic pathway was developed, including a correct culture temperature and photoperiod appropriate for the analyzed environment.

To preserve the conditions that were the most comparable to the natural conditions in a bath water in summer, cultures were incubated at $20^{\circ} \mathrm{C}$. This is a temperature that is typical of water on hot days. The length of a photoperiod typical of summer was retained: 17 day-hours and 7 night-hours. For the samples requiring the conditions of a swimming pool, artificial light was provided for 16 hours a day. The incubation temperature was maintained at $27^{\circ} \mathrm{C}$ (which is typical of a swimming pool) and at $35^{\circ} \mathrm{C}$ (which is characteristic for a warm Jacuzzi). In order to create conditions found in hot tap water distribution systems, a culture was run in complete darkness and at $40^{\circ} \mathrm{C}$. To 
meet the criteria typical of storage conditions for medium-mineralized bottled water, cultures were kept at $23^{\circ} \mathrm{C}$ in daylight.

\section{A technique for fungal counting and evaluation of gross morphological and microscopic morphological features}

A $5^{\circ}$ suspension (according to McFarland's scale) was prepared from each initial culture of the tested species and a 1:1,000 dilution was then performed. From the last dilution, $10 \mu \mathrm{l}$ was sampled on another 5 Petrie dishes with solid Sabouraud's medium prepared based on the tested water types. A drop of the suspension was distributed evenly with a sterile spreader and left to be absorbed. The plates were incubated at $20^{\circ} \mathrm{C}, 23^{\circ} \mathrm{C}, 27^{\circ} \mathrm{C}, 35^{\circ} \mathrm{C}$ and $40^{\circ} \mathrm{C}$. The cultures were stored for a maximum of 30 days and the growth rate of the colonies was assessed. Microcultures on Nickerson's agar (which was also prepared with the tested water types) were also set from the initial cultures. Microcultures were incubated at $20^{\circ} \mathrm{C}, 23^{\circ} \mathrm{C}, 27^{\circ} \mathrm{C}, 35^{\circ} \mathrm{C}$ and $40^{\circ} \mathrm{C}$ maintaining conditions that were analogous with those for Sabouraud's agar. After $48 \mathrm{~h}$ ( 2 days), $72 \mathrm{~h}$ ( 3 days), $154 \mathrm{~h}$ ( 7 days), $328 \mathrm{~h}$ (14 days) and $720 \mathrm{~h}$ (30 days), the growth rate and the capacity for blastospore, mycelium and chlamydospore formation were evaluated (Biedunkiewicz-Ziomek and Dynowska, 2004). Gross and microscopic features were observed and compared with descriptions of species depicted in the keys for identification of fungi (de Hoog et al., 2000; Lodder and Kreger-van Rij, 1965; Kurtzmann and Fell, 2000; Kurtzmann et al., 2011; Howard, 2003).

\section{Evaluation of enzymatic activity}

An API ZYM (bioMérieux) containing the substrates for detecting 19 hydrolases was used to evaluate the enzymatic activity of strains before and after culturing. The level of separated hydrolases was determined based on a five-degree color scale according to the manufacturer's recommendations.

\section{Results}

The experiment found that all microfungi retained their capacity for growth under controlled laboratory conditions.

The highest number of colony-forming units was recorded on the cultures set on Sabouraud's medium at $35^{\circ} \mathrm{C}$ and $40^{\circ} \mathrm{C}$. A slightly slower growth rate was detected at $20^{\circ} \mathrm{C}, 23^{\circ} \mathrm{C}$ and $27^{\circ} \mathrm{C}$ with the slowest growth being demonstrated at $4^{\circ} \mathrm{C}$. All fungi produced blastospores and pseudohyphae. The arrangement of blastospores on pseudohyphae was typical of the individual species. C. tropicalis (Fig. 1) and C. krusei (Fig. 2) produced longer pseudohyphae than under standard culture conditions at $37^{\circ} \mathrm{C}$. C. albicans (Fig. 3 and 4) and C. guilliermondii (Fig. 5 and 6) produced a lower number of blastospores although they retained a full capacity for growing typical pseudohyphae. Within a $4^{\circ} \mathrm{C}$ to $40^{\circ} \mathrm{C}$ incubation range, C. albicans (Fig. 7) did not produce intercalary and lateral chlamydospores, whereas terminal chlamydospores appeared after 7 days of incubation at lower temperatures: between $4{ }^{\circ} \mathrm{C}$ and $23^{\circ} \mathrm{C}$. At $20^{\circ} \mathrm{C}-23^{\circ} \mathrm{C}$, fungi multiplied, producing blastospores on shorter-than-usual pseudohyphae. The temperatures $35^{\circ} \mathrm{C}$ and $40^{\circ} \mathrm{C}$ resulted in a typical micromycelium morphology. Microfungi stored in filtered utility water types as a basis for cultures retained at $4^{\circ} \mathrm{C}$ a full capacity to produce biomass (vegetative cells). After 30 days, the 
level of cell survival was 30\% for Candida albicans and Candida krusei and 10\% for Candida guilliermondii and Candida tropicalis, regardless of incubation temperature.

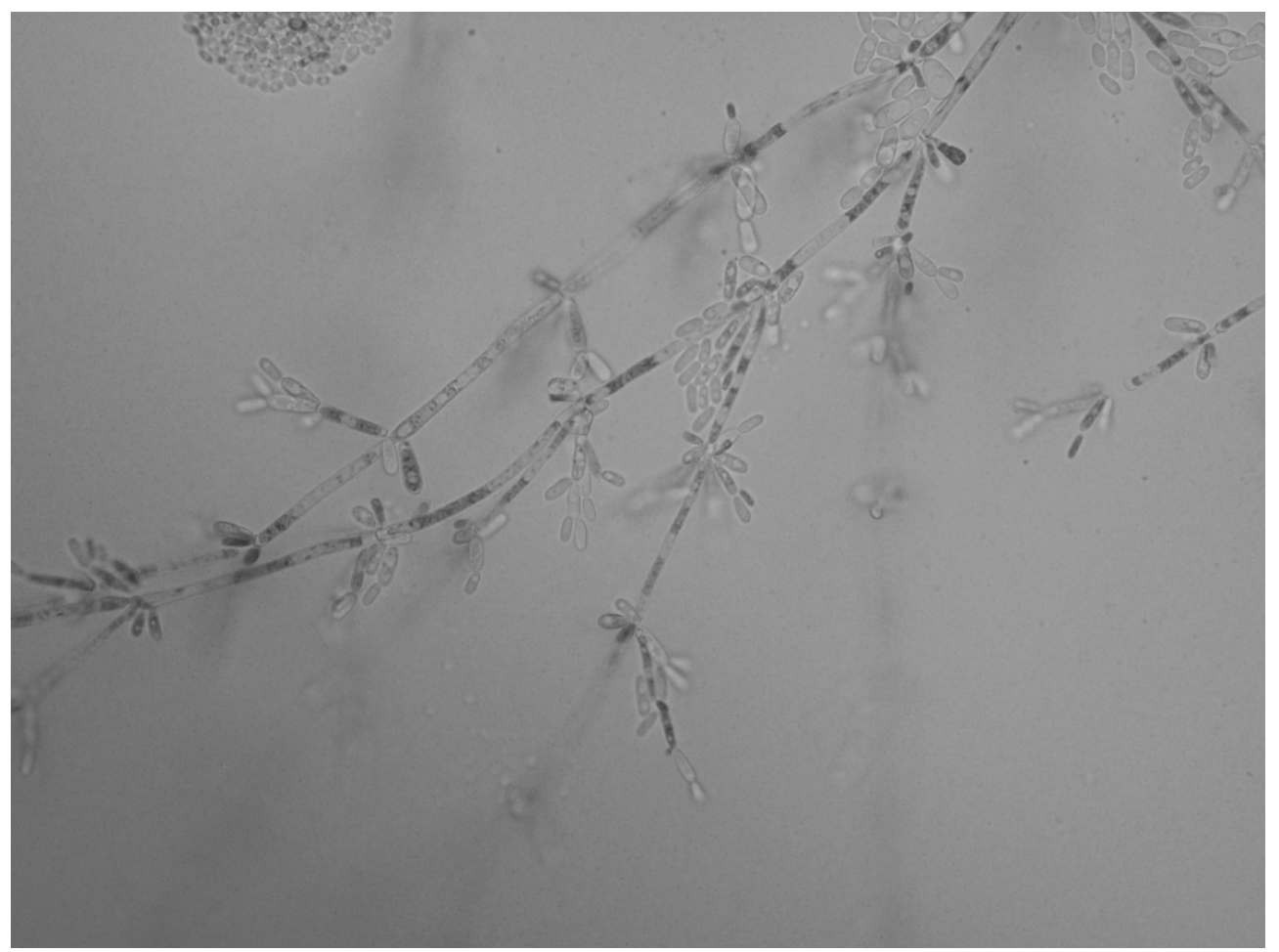

Figure 1. Candida krusei-microculture on the modified agar Nickerson, after $154 \mathrm{~h}$ incubation.

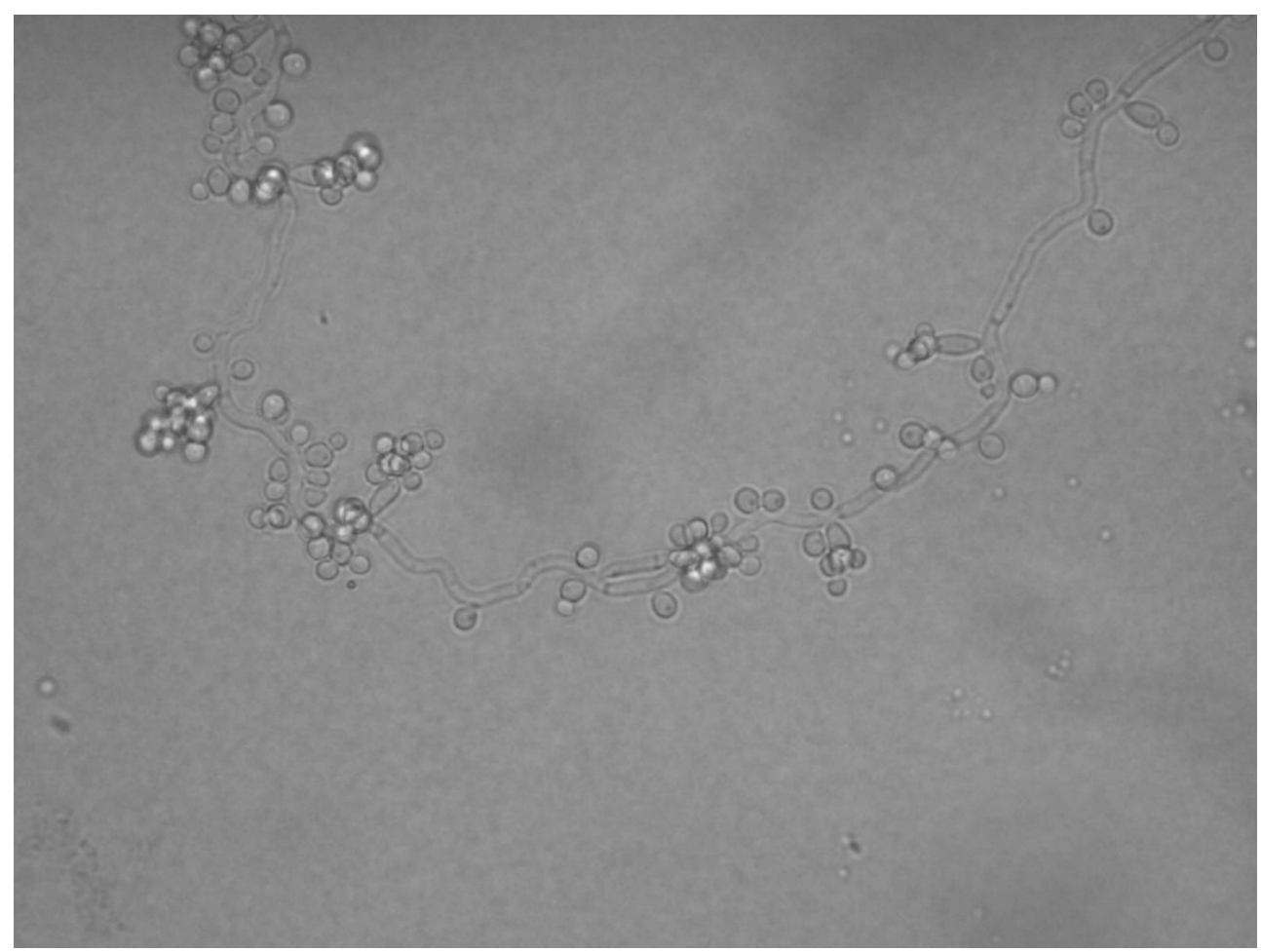

Figure 2. Candida tropicalis-microculture on the modified agar Nickerson, after $154 \mathrm{~h}$ incubation. 


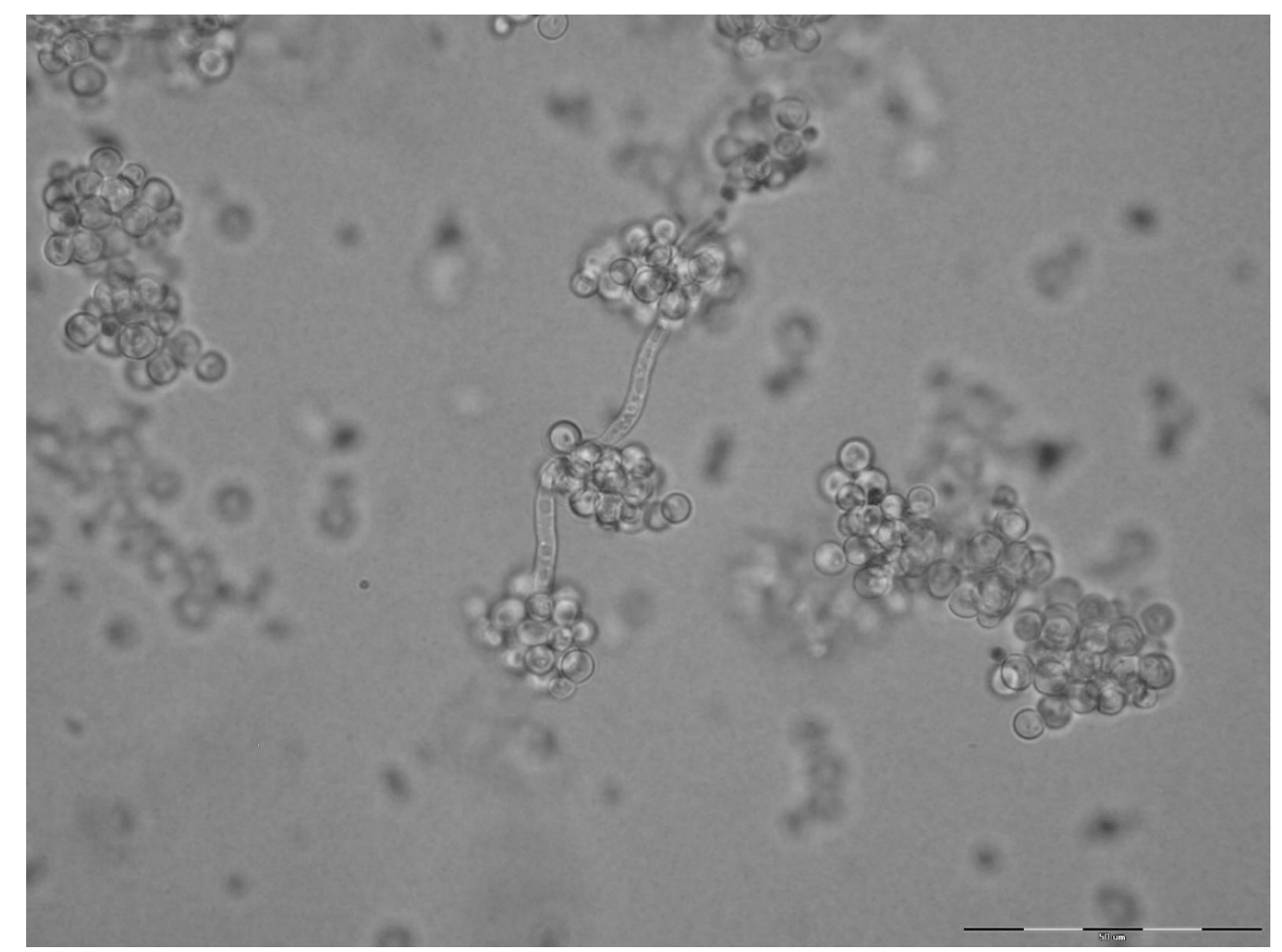

Figure 3. Candida albicans - microculture on the modified agar Nickerson, after $72 \mathrm{~h}$ incubation.

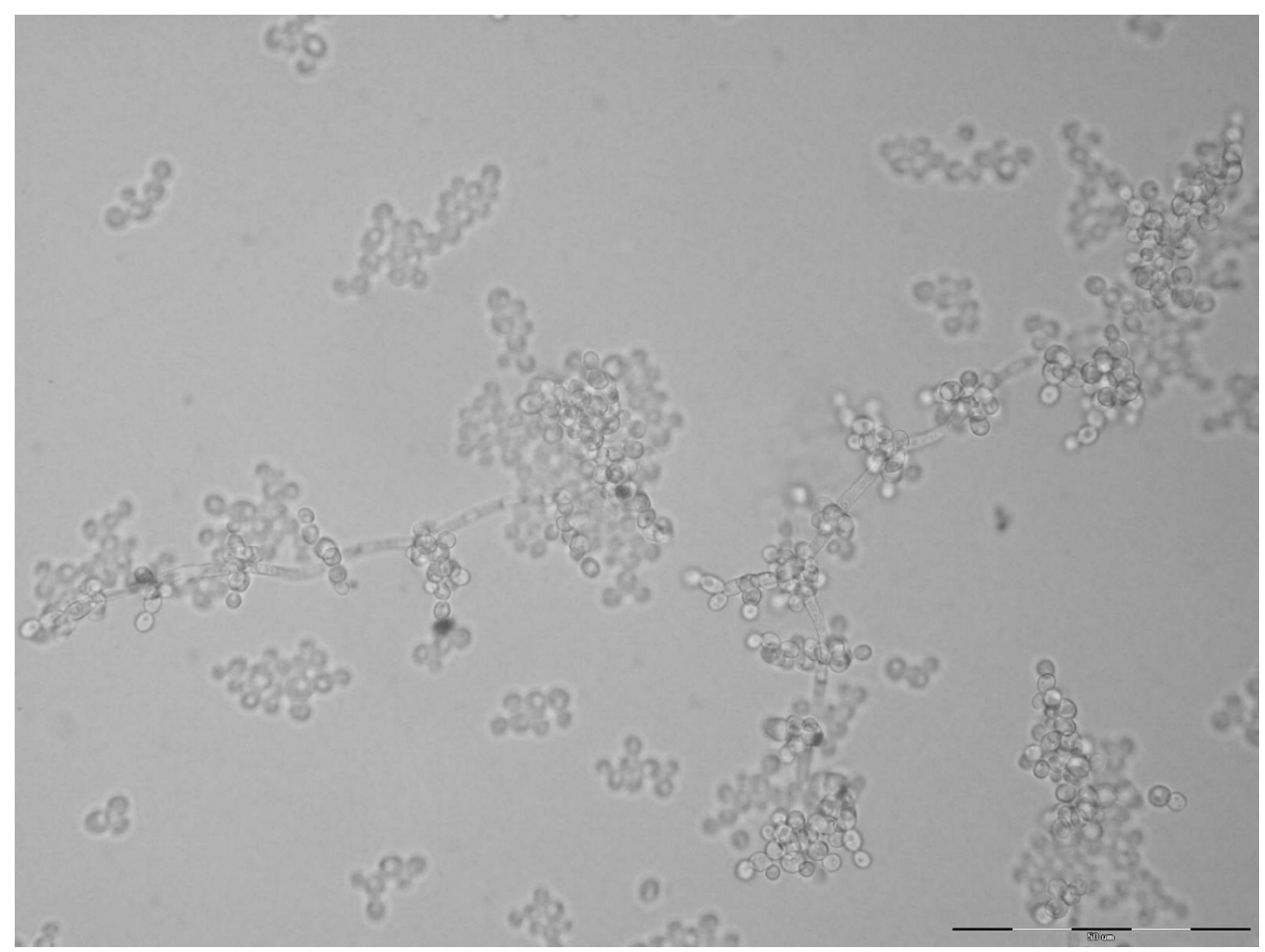

Figure 4. Candida albicans - microculture on the modified agar Nickerson, after $144 \mathrm{~h}$ incubation. 


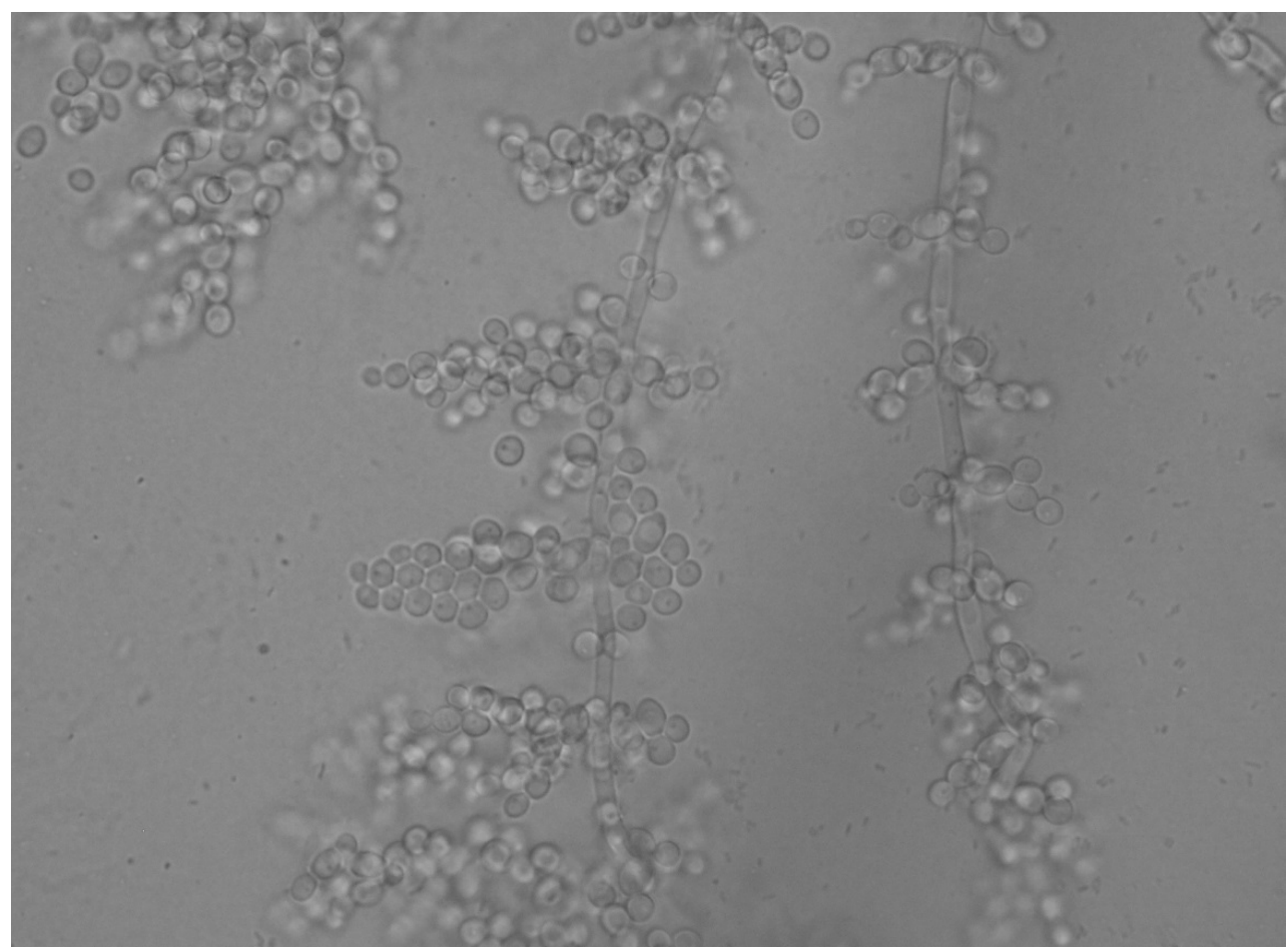

Figure 5. Candida guilliermondii-microculture on the modified agar Nickerson, after $72 \mathrm{~h}$ incubation.

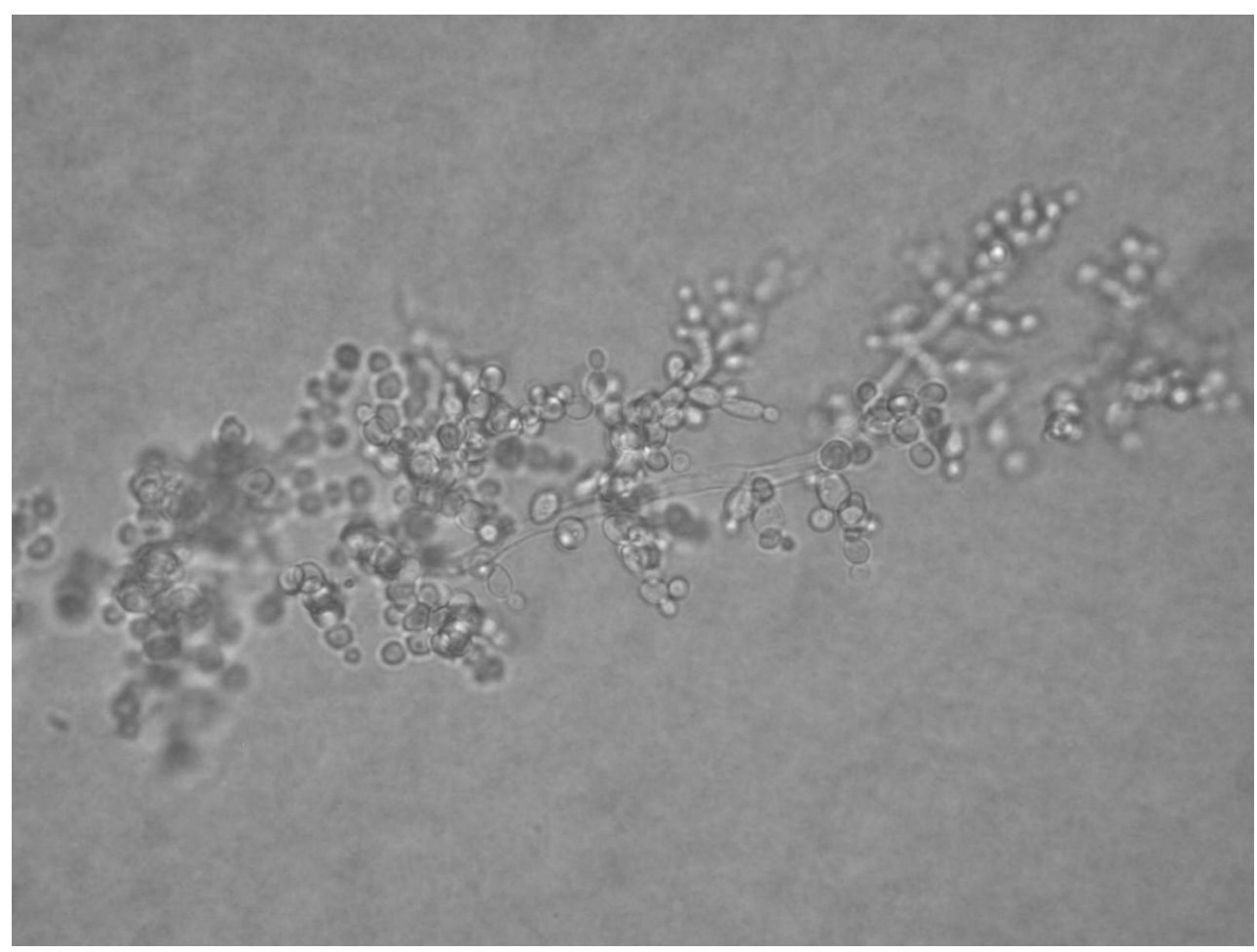

Figure 6. Candida guilliermondii - microculture on the modified agar Nickerson, after $154 \mathrm{~h}$ incubation. 


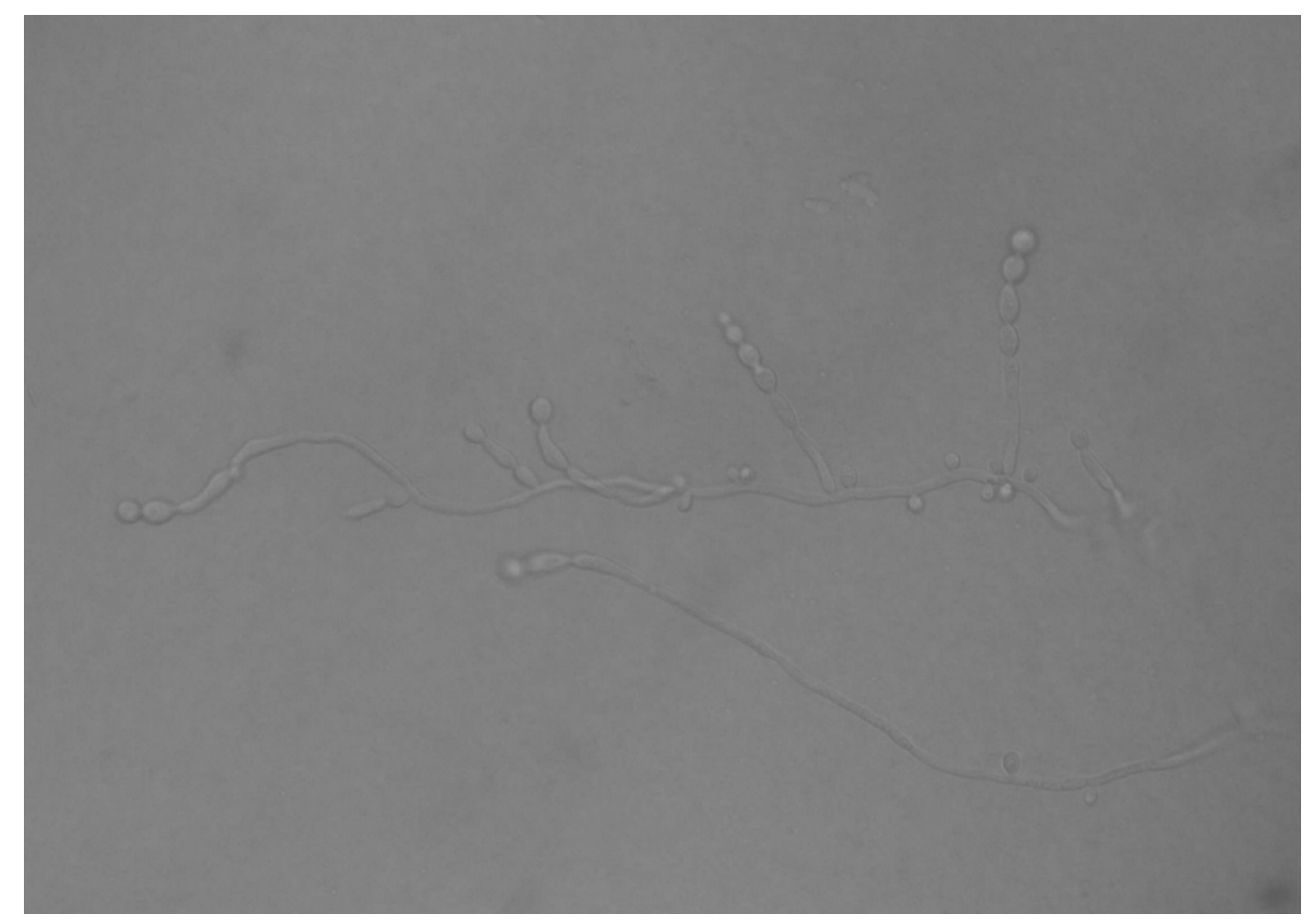

Figure 7. Candida albicans - microculture on the modified agar Nickerson, after $154 \mathrm{~h}$ incubation (pseudomycelium with chlamydospores).

The enzymatic activity of the investigated species was at a high level before multiplication and was reduced by approximately $5 \%$ after controlled multiplication under laboratory conditions. In all tested strains, the highest activity was recorded for acidic and alkaline phosphatase both before (20-35 nmol) and after the experiment (15-25 nmol). A slightly lower activity was detected for phosphohydrolase and esterase (21-30 nmol and 15-20 nmol, respectively, and 15-20 $\mathrm{nmol}$ and 10-20 nmol) as well as for leucine, valine and cysteine (from 15-20 nmol and 10-15 nmol). The other enzymes demonstrated activity at a levels lower than 5$10 \mathrm{nmol}$ (Table 1).

\section{Discussion}

Similar to all living organisms, fungi need water for vital biological activities and metabolic processes (Karch, 2008). Pollution of surface waters may negatively impact the condition and livability of the cells, causing stress and a change in the rate of biological processes; in extreme cases, they may destroy the cells and eliminate the entire population. The conducted studies provide an answer to the question of the degree to which water-inhabiting fungi are adapted to a changing environment and whether the same species that are regarded as potential pathogens in medical mycology are capable of surviving in waters with different physicochemical parameters. 
Table 1. Enzymatic activity of fungi tested before and after the multiplication in controlled laboratory conditions

\begin{tabular}{|c|c|c|c|c|c|c|c|c|c|c|c|c|c|c|c|c|c|c|c|c|c|}
\hline & \multirow{2}{*}{$\begin{array}{l}\text { Isolates } \\
\begin{array}{|c|c|}\text { Type of } \\
\text { water }\end{array} \\
\end{array}$} & \multicolumn{5}{|c|}{ Candida albicans } & \multicolumn{5}{|c|}{ Candida tropicalis } & \multicolumn{5}{|c|}{ Candida guilliermondii } & \multicolumn{5}{|c|}{ Candida krusei } \\
\hline & & I & II & III & IV & $\mathbf{V}$ & I & II & III & IV & V & I & II & III & IV & V & I & II & III & IV & $\mathbf{V}$ \\
\hline \multirow{6}{*}{ 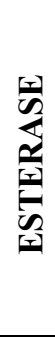 } & ALP & $(3 / 3)$ & $(3 / 3)$ & $(4 / 4)$ & $(5 / 4)$ & $(3 / 3)$ & $(2 / 1)$ & $(3 / 3)$ & $(4 / 4)$ & $(4 / 3)$ & $(2 / 1)$ & $(2 / 1)$ & $(2 / 1)$ & $(4 / 3)$ & $(3 / 3)$ & $(2 / 1)$ & $(2 / 2)$ & $(2 / 2)$ & $(4 / 4)$ & $(4 / 4)$ & $(2 / 2)$ \\
\hline & AcP & $(0 / 0)$ & $(0 / 0)$ & $(4 / 4)$ & $(4 / 3)$ & $(3 / 3)$ & $(0 / 0)$ & $(0 / 0)$ & $(3 / 3)$ & $(0 / 0)$ & $(0 / 0)$ & $(0 / 0)$ & $(0 / 0)$ & $(3 / 3)$ & $(0 / 0)$ & $(0 / 0)$ & $(0 / 0)$ & $(0 / 0)$ & $(4 / 3)$ & $(3 / 2)$ & $(0 / 0)$ \\
\hline & $\mathbf{P h}$ & $(0 / 0)$ & $(0 / 0)$ & $(4 / 3)$ & $(4 / 4)$ & $(0 / 0)$ & $(0 / 0)$ & $(0 / 0)$ & $(4 / 3)$ & $(0 / 0)$ & $(0 / 0)$ & $(0 / 0)$ & $(0 / 0)$ & $(2 / 2)$ & $(0 / 0)$ & $(0 / 0)$ & $(0 / 0)$ & $(0 / 0)$ & $(3 / 2)$ & $(0 / 0)$ & $(0 / 0)$ \\
\hline & Est & $(0 / 0)$ & $(0 / 0)$ & $(0 / 0)$ & $(0 / 0)$ & $(0 / 0)$ & $(0 / 0)$ & $(0 / 0)$ & $(0 / 0)$ & $(0 / 0)$ & $(0 / 0)$ & $(0 / 0)$ & $(0 / 0)$ & $(0 / 0)$ & $(0 / 0)$ & $(0 / 0)$ & $(0 / 0)$ & $(0 / 0)$ & $(0 / 0)$ & $(0 / 0)$ & $(0 / 0)$ \\
\hline & El & $(0 / 0)$ & $(0 / 0)$ & $(0 / 0)$ & $(0 / 0)$ & $(0 / 0)$ & $(0 / 0)$ & $(0 / 0)$ & $(0 / 0)$ & $(0 / 0)$ & $(0 / 0)$ & $(0 / 0)$ & $(0 / 0)$ & $(0 / 0)$ & $(0 / 0)$ & $(0 / 0)$ & $(0 / 0)$ & $(0 / 0)$ & $(0 / 0)$ & $(0 / 0)$ & $(0 / 0)$ \\
\hline & Lip & $(0 / 0)$ & $(0 / 0)$ & $(0 / 0)$ & $(0 / 0)$ & $(0 / 0)$ & $(0 / 0)$ & $(0 / 0)$ & $(0 / 0)$ & $(0 / 0)$ & $(0 / 0)$ & $(0 / 0)$ & $(0 / 0)$ & $(0 / 0)$ & $(0 / 0)$ & $(0 / 0)$ & $(0 / 0)$ & $(0 / 0)$ & $(0 / 0)$ & $(0 / 0)$ & $(0 / 0)$ \\
\hline \multirow{5}{*}{ 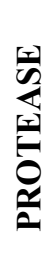 } & Leu & $(3 / 2)$ & $(2 / 2)$ & $(3 / 2)$ & $(3 / 3)$ & $(2 / 2)$ & $(3 / 2)$ & $(0 / 0)$ & $(3 / 2)$ & $(0 / 0)$ & $(2 / 2)$ & $(2 / 2)$ & $(2 / 1)$ & $(3 / 3)$ & $(0 / 0)$ & $(2 / 1)$ & $(2 / 2)$ & $(0 / 0)$ & $(3 / 3)$ & $(3 / 3)$ & $(2 / 2)$ \\
\hline & Val & $(0 / 0)$ & $(2 / 2)$ & $(0 / 0)$ & $(0 / 0)$ & $(2 / 2)$ & $(0 / 0)$ & $(0 / 0)$ & $(0 / 0)$ & $(3 / 2)$ & $(2 / 2)$ & $(0 / 0)$ & $(0 / 0)$ & $(0 / 0)$ & $(3 / 3)$ & $(0 / 0)$ & $(0 / 0)$ & $(0 / 0)$ & $(3 / 2)$ & $(0 / 0)$ & $(0 / 0)$ \\
\hline & Cys & $(3 / 2)$ & $(2 / 1)$ & $(3 / 2)$ & $(0 / 0)$ & $(0 / 0)$ & $(0 / 0)$ & $(2 / 2)$ & $(0 / 0)$ & $(0 / 0)$ & $(0 / 0)$ & $(0 / 0)$ & $(2 / 1)$ & $(3 / 3)$ & $(0 / 0)$ & $(0 / 0)$ & $(2 / 2)$ & $(2 / 2)$ & $(3 / 2)$ & $(0 / 0)$ & $(2 / 2)$ \\
\hline & Try & $(0 / 0)$ & $(0 / 0)$ & $(0 / 0)$ & $(0 / 0)$ & $(0 / 0)$ & $(0 / 0)$ & $(0 / 0)$ & $(0 / 0)$ & $(0 / 0)$ & $(0 / 0)$ & $(0 / 0)$ & $(0 / 0)$ & $(0 / 0)$ & $(0 / 0)$ & $(0 / 0)$ & $(0 / 0)$ & $(0 / 0)$ & $(0 / 0)$ & $(0 / 0)$ & $(0 / 0)$ \\
\hline & aChy & $(0 / 0)$ & $(0 / 0)$ & $(0 / 0)$ & $(0 / 0)$ & $(0 / 0)$ & $(0 / 0)$ & $(0 / 0)$ & $(0 / 0)$ & $(0 / 0)$ & $(0 / 0)$ & $(0 / 0)$ & $(0 / 0)$ & $(0 / 0)$ & $(0 / 0)$ & $(0 / 0)$ & $(0 / 0)$ & $(0 / 0)$ & $(0 / 0)$ & $(0 / 0)$ & $(0 / 0)$ \\
\hline \multirow{8}{*}{ 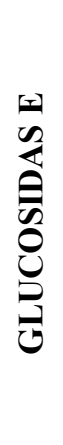 } & $\mathbf{\alpha G a}$ & $(0 / 0)$ & $(0 / 0)$ & $(1 / 0)$ & $(1 / 1)$ & $(0 / 0)$ & $(0 / 0)$ & $(0 / 0)$ & $(1 / 0)$ & $(1 / 1)$ & $(0 / 0)$ & $(0 / 0)$ & $(0 / 0)$ & $(1 / 0)$ & $(1 / 1)$ & $(0 / 0)$ & $(0 / 0)$ & $(0 / 0)$ & $(1 / 0)$ & $(1 / 1)$ & $(0 / 0)$ \\
\hline & $\boldsymbol{\beta G a}$ & $(0 / 0)$ & $(0 / 0)$ & $(1 / 0)$ & $(1 / 0)$ & $(0 / 0)$ & $(0 / 0)$ & $(0 / 0)$ & $(1 / 0)$ & $(1 / 0)$ & $(0 / 0)$ & $(0 / 0)$ & $(0 / 0)$ & $(1 / 0)$ & $(1 / 0)$ & $(0 / 0)$ & $(0 / 0)$ & $(0 / 0)$ & $(1 / 0)$ & $(1 / 0)$ & $(0 / 0)$ \\
\hline & BGk & $(0 / 0)$ & $(0 / 0)$ & $(0 / 0)$ & $(0 / 0)$ & $(0 / 0)$ & $(0 / 0)$ & $(0 / 0)$ & $(0 / 0)$ & $(0 / 0)$ & $(0 / 0)$ & $(0 / 0)$ & $(0 / 0)$ & $(0 / 0)$ & $(0 / 0)$ & $(0 / 0)$ & $(0 / 0)$ & $(0 / 0)$ & $(0 / 0)$ & $(0 / 0)$ & $(0 / 0)$ \\
\hline & $\alpha \mathbf{G l}$ & $(0 / 0)$ & \begin{tabular}{|l}
$(0 / 0)$ \\
\end{tabular} & $(0 / 0)$ & $(0 / 0)$ & $(0 / 0)$ & $(0 / 0)$ & $(0 / 0)$ & $(0 / 0)$ & $(0 / 0)$ & $(0 / 0)$ & $(0 / 0)$ & $(0 / 0)$ & $(0 / 0)$ & $(0 / 0)$ & $(0 / 0)$ & $(0 / 0)$ & $(0 / 0)$ & \begin{tabular}{|l|l}
$(0 / 0)$ \\
\end{tabular} & $(0 / 0)$ & $(0 / 0)$ \\
\hline & BGI & $(0 / 0)$ & $(0 / 0)$ & $(0 / 0)$ & $(0 / 0)$ & $(0 / 0)$ & $(0 / 0)$ & $(0 / 0)$ & $(0 / 0)$ & $(0 / 0)$ & $(0 / 0)$ & $(0 / 0)$ & $(0 / 0)$ & $(0 / 0)$ & $(0 / 0)$ & $(0 / 0)$ & $(0 / 0)$ & $(0 / 0)$ & $(0 / 0)$ & $(0 / 0)$ & $(0 / 0)$ \\
\hline & Nac & $(0 / 0)$ & $(0 / 0)$ & $(0 / 0)$ & $(0 / 0)$ & $(0 / 0)$ & $(0 / 0)$ & $(0 / 0)$ & $(0 / 0)$ & $(0 / 0)$ & $(0 / 0)$ & $(0 / 0)$ & $(0 / 0)$ & $(0 / 0)$ & $(0 / 0)$ & $(0 / 0)$ & $(0 / 0)$ & $(0 / 0)$ & $(0 / 0)$ & $(0 / 0)$ & $(0 / 0)$ \\
\hline & $\alpha \mathbf{M a}$ & $(0 / 0)$ & $(0 / 0)$ & $(0 / 0)$ & $(0 / 0)$ & $(0 / 0)$ & $(0 / 0)$ & $(0 / 0)$ & $(0 / 0)$ & $(0 / 0)$ & $(0 / 0)$ & $(0 / 0)$ & $(0 / 0)$ & $(0 / 0)$ & $(0 / 0)$ & $(0 / 0)$ & $(0 / 0)$ & $(0 / 0)$ & $(0 / 0)$ & $(0 / 0)$ & $(0 / 0)$ \\
\hline & $\alpha \mathbf{F u}$ & $(0 / 0)$ & $(0 / 0)$ & $(0 / 0)$ & $(0 / 0)$ & $(0 / 0)$ & $(0 / 0)$ & $(0 / 0)$ & $(0 / 0)$ & $(0 / 0)$ & $(0 / 0)$ & $(0 / 0)$ & $(0 / 0)$ & $(0 / 0)$ & $(0 / 0)$ & $(0 / 0)$ & $(0 / 0)$ & $(0 / 0)$ & $(0 / 0)$ & $(0 / 0)$ & $(0 / 0)$ \\
\hline
\end{tabular}

Legend: I - lake, II - swimming pool, III - Jacuzzi, IV - drinking tap, V - bottled water; (on/off) - (before/ after the end experiment); 0 - lack of activity (0 nmol), 1 - very low activity (1$10 \mathrm{nmol}), 2$ - low activity (11-20 mol), 3 - medium activity (21-30 mol), 4 - high activity (31-40 mol), 5 - very high activity (41 nmol) 
The hydrosphere is the biggest reservoir of fungi. Apart from harmless saprophytes, species thought to be pathogenic are also isolated from reservoirs which they enter together with surface flows or municipal sewage. The numbers of fungi and their enzymatic activity are very important in mycological analyses of aquatic ecosystems. These features allow a determination of the capacity of fungi to become involved in ecophysiological relations with other microorganisms, which is of fundamental importance in a description of aquatic ecosystem dynamics and the functioning of the entire microbiological loop (Dynowska and Biedunkiewicz, 2013).

Potential pathogens may also enter the water from the skin and mucosal membranes of asymptomatic carriers (Biedunkiewicz, 2007). Adherence to the host's cells is essential for the survival of fungi on the mucosal membrane in a symbiotic relation or by causing infections. A strong contact between the surface of epithelial cells and the layers of an adhering fungus then develops. Forms with higher metabolic activity adhere more strongly, which is important in the case of pathogenic fungi. Dimorphism, observed in some Candida species, plays an important role in fungi survival in different environments. Two forms may occur: a more enzymatically-active mycelial form (M) which is thought to be more pathogenic, and a yeast-like form (Y) that is primal and has a high capacity for multiplication, adherence and biofilm formation (Ejdys, 2009). Under microaerophilic conditions, blastospores elongate and a blastospore form transforms into a pseudomycelial form. Until recently, it has been thought that one of the above-mentioned forms is isolated from the natural environment (from the hydro-, litho- or aerosphere) or from the mucosal membranes in humans. In recent years, it has been observed that both developmental forms are detected in samples from different ecosystems. Furthermore, their presence in healthy individuals - asymptomatic carriers (Biedunkiewicz, 2007) and in diseased persons (Cierech et al., 2012) cannot be excluded, which may result in their occurrence in waters used for recreational purposes (Biedunkiewicz et al., 2007; Biedunkiewicz et al., 2013; Biedunkiewicz, 2007). When assessing the purity of waters for their bathing suitability, the presence of fungi poses a significant epidemiological risk.

Although to date, no cases of fungal infection in the aquatic environment have been documented, such a situation cannot be excluded because microfungi display high ecophysiological flexibility. Previous personal studies indicated the rate and intensity of fungal growth across a wide range of temperatures (Biedunkiewicz and Ejdys, 2011). Yeasts from cold environments (the psychro- or cryosphere) demonstrated relatively rapid and abundant growth at approximately $1,500 \mathrm{CFU} / \mathrm{dm}^{3}$ after 24-hour incubation at $37^{\circ} \mathrm{C}$ (human body temperature) (Biedunkiewicz and Ejdys, 2011). This demonstrates the rapid acclimatization of these fungi to new thermal conditions, which is more proof of their high adaptive capacity.

Yeasts and yeast-like fungi are regarded as expansive microfungi which are very active in transforming an occupied ecological niche (Dynowska, 1995). High hydrolytic activity is a reliable indicator of conquering new habitats (Dynowska et al., 2002). In conjunction with livability and the growth rate of fungal multiplication, this activity describes the adaptive capacities of individual fungal species in changing environments (Dynowska and Biedunkiewicz, 2013). The ability of fungi to adapt to new conditions by increasing the growth rate of biomass, formation of pseudomycelium and the production of a variety of hydrolytic enzymes is particularly important when fungi penetrate into organ onthocenoses or onto the surface of mucosal membranes through an infection gate. Previous personal studies (Dynowska et al., 2005) demonstrated the 
high production of the same groups of enzymes isolated from different types of water which had been cultured on standard media. In the present study, despite using modified media with different types of filtered water, a comparably high level of hydrolytic activity was recorded. This indicates the need to investigate microfungi through their capacity to cross protective barriers and to infect humans. A high level of hydrolytic enzyme production is of special relevance for the analysis of pathogenicity of Candida fungi, which includes most potential pathogens. The high level of enzymes categorized as acidic and alkaline phosphatases and proteases, as evidenced in the present study, is particularly important since they may initiate damage to the epithelial cells, thus enabling invasion and penetration of fungi deep into the tissues. A relatively high level of esterase (classified in the group of lipases) is also important in the first phase of infection (Borst and Fluit, 2003; Schaller et al., 2005; Deorukhkar et al., 2014).

Studies of different physiological capacities in fungi isolated from the aquatic environment allow determining whether a given species poses a real epidemiological threat to water users. On the surface of mucosal membranes, fungi may coexist with other microorganisms in different biological systems as opportunist, parasitic or pathogenic forms. Conditions in human onthocenoses allow microfungi to survive and multiply and, in extreme situations, to penetrate the tissues and to cause mycosis.

The variability of fungal ecophysiology in their adaptation to the environment is the best survival strategy (Dynowska, 2008). Long-term observations carried out to date in laboratories have been limited to an evaluation of the survival rate of microfungal cultures in sterile distilled water with the method by Castellani (Hartung de Capriles et al., 1989). These observations conducted at $24-28^{\circ} \mathrm{C}$ for 20 years revealed a survival rate of microfungi at $62 \%$. The species that were investigated in the present study (Candida albicans, C. guilliermondii, C. tropicalis and C. krusei) according to Hartunda de Capriles et al. (1989) demonstrated survival lasting from zero (C. krusei) up to 19-20 years (C. guilliermondii and C. tropicalis). C. albicans, the most commonly-detected pathogen, survived for only 3 years. However, in cultures capable of further growth, there was $100 \%$ livability of the examined strains. When testing Candida albicans under starvation in different types of water and at $25^{\circ} \mathrm{C}$ (seawater, drinking water and precipitation water) in each water type, a reduction in livability was recorded after approximately one month (Chaieb et al., 2011).

Under conditions simulating the natural environment, the capacity of microfungi for an increased growth rate of biomass and an ability to produce pseudomycelium were observed. This indicates an extended capacity to conquer new substrates, including living organisms. Standard cultures (run in the recommended rage of temperatures: at $25^{\circ} \mathrm{C}$ and $37^{\circ} \mathrm{C}$ and on media as suggested in mycological diagnostics) allowed the gross features of grown colonies to be determined. The observations of inoculates in microcultures on Nickerson's agar in humid chambers reveal morphological features. Shorter distances than those usually seen in cultures between blastospores being formed on pseudohyphae indicate an increased rate of vegetative cell biomass production. The production of intercalary and lateral chlamydospores was inhibited at incubation across the whole range of temperatures while terminal chlamydospores occurred after a week of incubation at $4^{\circ} \mathrm{C}-23^{\circ} \mathrm{C}$. This indicates favorable conditions for the growth of Candida albicans that was capable of chlamydospore production.

Photoperiod is another factor impacting living organisms. The available literature lacks long-term studies on this phenomenon and fungi that are relevant in medical mycology (Dynowska, 1993b). There are only reports on the impact of day and night 
duration on phytopathogenic microfungi in correlation with the growth of a host (Jerzy, 2003).

The different culture variants that were adopted in the present study allowed us to select habitats in which attention should be paid to the presence of fungi. These conditions arguably include waters with increased temperatures, such as water in a warm Jacuzzi or tap water. The capacity for growth typical of a given species, multiplication and formation of well-developed pseudomycelium at higher temperatures provides a basis for including selected Candida species as proposed bioindicators of warm aquatic ecosystems. Although one should not indiscriminately relate the results recorded under laboratory conditions to the natural aquatic environment, it is possible to determine in which types of water fungi retain all ecophysiological features that are typical of potential pathogens.

The ecophysiological features (multiplication rate, enzymatic activity, capacity for pseudomycelium formation) selected for analyses indicate that microfungi should be considered to be pathogenic factors whose presence in thermal and recreational waters disqualifies them from public use. Based on the conducted experiment, it was found that regular mycological monitoring should be performed in swimming pool water, especially in a warm Jacuzzi and in drinking tap water. Moreover, constant mycological studies of baths during summer due to their massive use by people should be provided. In this context, water is a site of fungal migration. However, one cannot exclude the role of water as a "habitat" for potential pathogens since, depending on the type and volume as well as the availability of organic matter, numerous fungal species may find favorable trophic and growth conditions, which directly affect the rate of metabolic processes.

Acnowledgements. This study was conducted within the framework of the grant: NN 305162239.

\section{REFERENCES}

[1] Biedunkiewicz, A. (2007): Fungi in the sanitary-epidemiological evaluation of the selected resort. - In: Garbacz, J. (ed.) Diagnosis of the environment, research methods prediction, The work of the Committee of Ecology and Environment Science Society part. I. Bydgoszcz. 107-121 (In Polish).

[2] Biedunkiewicz, A. (2009): Microfungi of municipal fountains in environmental monitoring - an epidemiological threat. - Ochrona Środowiska i Zasobów Naturalnych. 41: 163- 171 (In Polish).

[3] Biedunkiewicz, A. (2011): Selected microfungi postulated as bioindicators in the assessment of waters purity in Poland. - In: Innovation processes in ICSTI community. Production of clean water: challenges and innovative solutions. Fourth ed. 115-124.

[4] Biedunkiewicz, A. (2007): Yeast-like fungi isolated in students. - Acta Mycologica 42 (1): 141-149.

[5] Biedunkiewicz, A., Dynowska, M., Ejdys, E., Sucharzewska, E. (2013): Species diversity of yeast-like fungi in some eutrophic lakes in Olsztyn. - Acta Mycologica 48 (1): 61-71.

[6] Biedunkiewicz, A., Ejdys E. (2011): Icicles as carriers of yeast-like fungi potentially pathogenic to human. - Aerobiologia 27 (4): 333-337.

[7] Biedunkiewicz, A., Schulz Ł. (2012): Fungi of the genus Exophiala in tap water potential etiological factors of phaeohyphomycoses. - Mikologia Lekarska 19 (1): 23-26.

[8] Biedunkiewicz, A., Silicki, A., Mazurkiewicz-Zapałowicz, K. (2007): Yeast-like fungi in selected bath of Szczecin. - Limnological Review 3: 3-10. 
[9] Biedunkiewicz-Ziomek, A., Dynowska, M. (2004): Candida dubliniensis Sullivan et al. a new species in the human respiratory system. - Acta Mycologica 39 (1): 7-11.

[10] Bis, H., Frączek, K., Mędrela-Kuder, E., Ropek, D. (2013): Mycological quality of water within municipal landfill and in its surroundings. - Ecological Chemistry and Engineering 20 (2): 149156.

[11] Borst, A., Fluit, C. (2003): High level of hydrolytic enzymes secreted by Candida albicans isolated in respiratory infections. - Journal of Medical Microbiology 52: 971974.

[12] Chaieb, K., Kouidhi, B., Zmantar, T., Mahdouani, K., Bakhrouf, A. (2011): Starvation survival of Candida albicans in various water. Microcosms. - Journal of Basic Microbiology 51 (4): 357-363.

[13] Cierech, M., Szczypińska, A., Wróbel, K., Gołaś, M. (2012): Methods of laboratory diagnosis of fungal infection in the mucous membranes of the oral cavity in patients consuming restorations moving. - Protetyka Stomatologiczna LXII, 3, 165-172. (In Polish).

[14] De Hoog, G.S., Guarro, J., Gene, J., Figuerras, M.J. (2000): Atlas of clinical fungi. Centraalbureau voor Schimmelcultures/ Universitat Rovira and Virgili, Reus, Spain.

[15] Deorukhkar, S.C., Saini, S., Mathew, S. (2014): Virulence factor contributing to pathogenicity of Candida tropicalis and its antifungal susceptibility profile. - International Journal of Microbiology, doi: http://dx.doi.org/10.1155/2014/456878.

[16] Dynowska, M., Biedunkiewicz, A. (2013): Microfungi as bioindicators. - In: Ciecierska, H. and Dynowska, M. (eds) Biological methods of environmental assessment. Vol. II. Aquatic ecosystems. Methodological manual. Mantis Olsztyn, 284-311. (In Polish).

[17] Dynowska, M. (2008): Current views on taxonomy, origin and nature of the fungus. - In: Baran E., (ed.) Mycology - what's new? - Cornetis, Wrocław, 127-137. (In Polish).

[18] Dynowska, M. (1993a): Importance of yeast-like fungi in the evaluation of water purity. In: Microbiological indicators of water purity. Environmental Analyses, PIOŚ, Environ Monit Libr, Warszawa. 77-81. (In Polish).

[19] Dynowska, M. (1993b): The rate of growth of Candida albicans (Robin, 1853) and Candida stellatoidea (Martin et Jones, 1938) isolated from the human respiratory system. - Wiadomości Parazytologiczne 39 (4): 383-390. (In Polish).

[20] Dynowska, M. (1995): Yeast and yeast-like fungi as pathogens and bioindicators of aquatic ecosystems. - Studia i Materiały WSP. Olsztyn.77. (In Polish).

[21] Dynowska, M., Biedunkiewicz, A., Ejdys, E. (2001): Pathogenic Yeast - Like Fungi with Bio - Indicator Properties. - Polish Journal of Environmental Studies Supl. I, 13- 16.

[22] Dynowska, M., Biedunkiewicz, A., Sucharzewska, E. (2002): Participation of yeast - like fungi in respiratory system diseases tuberculosis and neoplasms. - Acta Mycologica 37 (1/2): 117-122.

[23] Dynowska M., Biedunkiewicz-Ziomek, A., Kisicka, I. (2005): Eco-physiological differentiation of yeast-like fungi from different aquatic ecosystems. - Ecohydrology and Hydrobiology 5 (2): 147-153.

[24] Dynowska, M., Meissner, W., Pacyńska, J. (2013): Mallard duck (Anas plathyrhynchos) as a potential in the epidemiological chain mycoses originating from water reservoirs. Bulletin of the Veterinary Institute in Pulawy 57 (3): 323 - 328.

[25] Ejdys, E. (2009): Survival of fungi of the genus Candida and safety in the workplace in the mycological laboratory university. - Medycyna Pracy 60 (1): 1-5. (In Polish). 27

[26] Hartung De Capriles, C., Mata, S., Middelveen, M. (1989): Preservation of fungi in water (Castellani): 20 years. - Mycopathologia 106: 73-79.

[27] Howard, D. H. (2003): Pathogenic fungi in humans and animals. - Marcel Dekker, Inc., New York.

[28] Jerzy, M. (2003): Influence of alternating photoperiod on the flowering small-flowered chrysanthemum cultivars grown under protection. - Acta Scientiarum Polonorum 2 (1): 47-54. (In Polish). 
[29] Karch, C. (2008): Water and fungi. - Environmental Reporter 6 https://www.emlab.com/s/sampling/env-report-02-2008.html.

[30] Kiziewicz, B. (2007): The use of fungi to assess the cleanliness of surface water and groundwater basin Supraśl. - Habilitation thesis. Białystok. (In Polish).

[31] Kurtzmann, C.P., Fell, J.W. (2000): The yeasts, A Taxonomic Study. 4th ed. - Elsevier. Amsterdam.

[32] Kurtzmann, C.P., Fell, J.W., Boekhout, T. (2011): The Yeast. A taxonomic study. 5th ed. - Elsevier - Tokyo.

[33] Lodder, J., Kreger-van Rij, N.J.W. (1967): The yeasts. A Taxonomic study. - North Holland Publishing Company, Amsterdam.

[34] Parveen, S., Lanjewar, S., Sharma, K., Kutti, U. (2011): Isolation of fungi from the surface water of river. - Journal of Experimental Sciences 2 (10): 58-59.

[35] Rasti, S., Ali Assadi, M., Iranshahi, L., Saffari, M., Reza Gi-Lasi, H., Pourbabaee, M. (2012): Assessment of Microbial Contamination and Physicochemical Condition of Public Swimming Pools in Kashan, Iran. - Jundishapur Journal of Microbiology 5 (3): $450-455$.

[36] Schaller, M., Borelli, C., Korting, H.C., Hube, B. (2005): Hydrolytic enzymes as virulence factors of Candida albicans. - Mycoses 48 (6): 365 - 377.

[37] Shearer, C.A., Descals, E., Kohlmeyer, B., Kohlmeyer, J., Marvanova, L., Padgett, D., Porter, D., Raja, H.A., Schmit, J.P., Thorton, H.A. (2007): Voglymayr H. Fungal biodiversity in aquatic habitats. - Biodiversity Conservation 16: 49-67.

[38] Vogel, C., Rogerson, A., Schatz, S., Laubach, H., Tallman, A., Fell, J. (2007): Prevalence of yeasts in beach at three bathing beaches in South Florida. - Water Research 41 (9): $1915-1920$.

[39] Wurzbacher, C.M., Bärlocher, F., Grossart, H.-P. (2010): Fungi in lake ecosystems. Aquatic Microbial Ecology 59: 125 - 149. 